\title{
HUBUNGAN PENGETAHUAN DAN SIKAP PASIEN GAGAL GINJAL KRONIK (GGK) DENGAN KEPATUHAN DALAM MENJALANI TERAPI HEMODIALISA DI RUANGAN HEMODIALISA RSUP HAJI ADAM MALIK MEDAN TAHUN 2014
}

\author{
Soep \\ Staf Poltekkes Kemenkes Jurusan Keperawatan Medan
}

\begin{abstract}
Abstrak
Kasus gagal ginjal kronik di dunia meningkat, saat ini meningkat lebih dari 50\% dari 6.840.507.003 miliar warga dunia. Tanpa pengendalian yang cepat dan tepat kemungkinan tahun 2015 jumlah pasien yang menbutuhkan cuci darah diperkirakan 36 juta penduduk dunia. Penderita gagal ginjal kronik Di Amerika Serikat setip tahun ada sekitar 20 juta orang dewasa menderita penyakit ginjal kronik, dan harus melakukan hemodialisa (Seoleman, 2008). Penelitian ini bertujuan untuk mendapatkan gambaran umum tentang Hubungan pengetahuan dan sikap pasien gagal ginjal kronik terhadap kepatuhan dalam menjalani terapi hemodialisa di ruang hemodialisa RSUP H. Adam Malik. Jenis penelitian ini merupakan penelitian analitik kuantitatif dengan menggunakan desain penelitian cross-sectional dengan jumlah responden berjumlah 86 orang yang bertujuan untuk menganalisa hubungan pengetahuan dan sikap pasien Gagal ginjal kronik terhadap kepatuhan dalam menjalani terapi hemodialisa hasil penelitian yang dilakukan diruangan hemodialisa RSUP H. Adam Malik Medan Tahun 2014, diketahui bahwa mayoritas pasien memiliki sikap yang positif dengan kepatuhan terapi hemodialisa yang baik sebanyak 23 pasien, dan responden yang memilki sikap negatif dan patuh terhadap pelaksanaan hemodialisa sebanyak $10(11,6 \%)$. Berdasarkan hasil analisis chi-square hubungan sikap terhadap kepatuhan hemodialisa diperoleh nilai p-value : 2,22 berarti $p>$ 0,05 . Hal ini menunjukkan secara statistik bahwa tidak terdapat hubungan yang bermakna antara sikap dengan kepatuhan hemodialisa.
\end{abstract}

Kata Kunci : Pengetahuan, Sikap, Hemodialisa

\section{PENDAHULUAN}

Ginjal merupakan organ sistem perkemihan (tractus urinirius) yang bertugas menyaring cairan, sampah metabolisme dari dalam tubuh seperti diketahui setelah sel-sel tubuh mengubah makanan menjadi energi, maka akan dihasilkan pula sampah sebagai hasil sampingan dari proses metabolisme tersebut yang harus dibuang segera agar tidak meracuni tubuh (Vita Healh, 2008).

Gagal ginjal (renal failure) adalah kasus penurunan fungsi ginjal yang terjadi secara akut (kambuhan) maupun kronis (menahun). Dikatakan gagal ginjal akut (acute renal failure), tetapi kemudian dapat kembali normal setelah penyebabnya dapat segera diatasi. Gagal ginjal kronis hampir sama dengan penyakit hipertensi, dimana merupakan penyakit ikutan yang saling berkaitan, termasuk silent killer yaitu penayakit yang perlahan-lahan tetapi mematikan. Menurut Tunggul (2010) kalau dulu penderita radang ginjal kronis tahap akhir disebabkan oleh radang ginjal menahun. Sekarang penyebabnya lebih banyak ke komplikasi penyakit metabolik dan penyakit generatif.
Kasus gagal ginjal kronik di dunia meningkat, saat ini meningkat lebih dari 50\% dari 6.840.507.003 miliar warga dunia. Tanpa pengendalian yang cepat dan tepat kemungkinan tahun 2015 jumlah pasien yang menbutuhkan cuci darah diperkirakan 36 juta penduduk dunia. Penderita gagal ginjal kronik Di Amerika Serikat setip tahun ada sekitar 20 juta orang dewasa menderita penyakit ginjal kronik, dan harus melakukan hemodialisa (Seoleman, 2008).

Indonesia termasuk negara dengan tingkat penderita gagal ginjal yang cukup tinggi. Menurut data dari penetri (Persatuan Nefrologi Indonesia) diperkirakan ada 70 ribu penderita gagal ginjal di Indonesia setiap tahunnya, Indonesia termasuk negara dengan tingkat penderita gagal ginjal kronik cukup tinggi. Namun yang terdeteksi menderita gagal ginjal kronis tahap terminal dari mereka yang menjalani cuci darah (hemodialisa) hanya sekitar 4 ribu-5 ribu saja (Penetri, 2011).

Penderita gagal ginjal kronik Di Sumatera Utara mencapai 2260 orang, dan harus melakukan cuci darah (hemodialisa) salah satu faktor penyebab meningkatnya angka penderita gagal ginjal dari tahun ke tahun salah satunya kerena kurangnya kesadaran 
masyarakat terhadap infeksi dini penyakit tersebut (Rully, 2011).

Dari survey komunitas yang dilakukan perhimpunan nefrologi indonesia (PERNEFRI) didapatkan bahwa $12,5 \%$ dari populasi sudah mengalami penurunan fungsi ginjal, yang ditandai oleh adanya proteinuria ysng persisten laju filtrasi glomerulus (LFG) bila jumlah penduduk indonesia mengalami penurunan fungsi ginjal. Hasil survey dari berbagai pusatdialysis didapatkan kejadian baru penyakit gagal terminal kronik yang memerlukan dialysis sebesar $30,7 \%$ perjuta penduduk. Berarti setiap tahun terdapat 7.400 pasien baru penyakit gagal terminal akut (PERNEFRI, 2012).

Menurut Suhud, kepala Yayasan Ginjal Diatrash Indonesia (YGDI) jumlah pasien gagal ginjal saat ini diperkirakan 60.000 orang dengan pertambahan 4.400 baru setiap tahunnya. Di Indonesia jumlah pasien ginjal April 2006 berjumlah 150 orang akan tetapi yang membutuhkan terapi fungsi ginjal seperti hemodialisa mencapai 3000 orang (YGDI, 2007). Berdasarkan data yang diperoleh Yayasan Ginjal Indonesia (YAGINA) pada tahun 2007 terdapat $6.7 \%$ penduduk Indonesia sudah mempunyai gangguan fungsi ginjal dengan tingkatan sedang sampai berat, dengan kecenderungan yang meningkat sesuai dengan kemajuansebuah negara yang mengubah konsumsi masyarakatnya. Menurut ketua YAGINA Chaerul (2007) di Indonesia sekarang ini terdapat 70 ribu penderita gagal ginjal yang perlu mendapatkan perawatan berupa dialisis rutin maupun cangkok ginjal. Berdasarkan data Departemen Kesehatan pada tahun 2006, penyakit gagal ginjal menduduki no.4 angka penyebab kematian di rumah sakit Indonesia (DEPKES, 2007).

Pada pasien gagal ginjal kronik terdapat tiga pilihan terapi pengganti untuk mengatasi masalah yang ada yaitu; tidak diobati, dialisis kronis (dialisis peritoneal/ hemodialisa), serta transplantasi. Terapi pengganti yang menjadi pilihan utama dan merupakan metode perawatan umum untuk pasien gagal ginjal adalah hemodialisa. Hemodialisa merupakan suatu proses yang digunakan pada pasien dalam keadaan sakit akut maupun kronik dan memerlukan terapi dialisis jangka pendek atau terapi jangka panjang atau terapi permanen. Pada penderita gagal ginjal kronik, hemodialisis dapat mencegah kematian. Namun demikian, hemodialisis tidak menyembuhkan atau memulihkan penyakit ginjal dan tidak mampu mengimbangi hilangnya aktivitas metabolik atau endokrin yang dilaksanakan ginjal dan dampak dari gagal ginjal serta terapinya terhadap kualitas hidup pasien. Pasien gagal ginjal yang menjalani hemodialisa, membutuhkan waktu 12-15 jam untuk dialisa setiap minggunya, atau paling sedikit 3-4 jam per kali terapi (Bare \& Smeltzer, 2002).

Bila seseorang mengalami penyakit ginjal kronik sampai pada stadium akhir atau telah mengalami penyakit ginjal kronik (gagal ginjal) dimana laju filtrasi glomerulus (15 ml/menit) ginjal tidak mampu lagi menjalakan seluruh fungsinya dengan baik maka dibutuhkan terapi untuk menggantikan fungsi ginjal. Hingga saat ini dialisis dan transplantasi ginjal adalah tindakan yang efektif sebagai terapi untuk gagal ginjal kronis tahap terminal (Cahyaningsih, 2009).

Hemodialisa merupakan pengobatan untuk mengganti sebagian faal ginjal pada keadaan gagal ginjal. Pada proses ini zat-zat yang tidak diperlukan tubuh, yang dapat meracuni tubuh dan seharusnya dapat keluar bersama urin dibersihkan melalui penggunaan mesin dan ginjal buatan (dialeser). Hemodialisa ini dapat dilakukan untuk gagal ginjal akut maupun kronik. Bagi penderita gagal ginjal kronis, hemodialisa akan mencegah kematian. Namun demikian, hemodialisa tidak menyembuhkan dan tidak mampu mengimbangi hilangnya aktifitas metabolik atau endokrin yang dilaksanakan ginjal dan dampak dari gagal ginjal serta terapinya terhadap kualitas hidup pasien. Pasien-pasien ini harus menjalani terapi dialisis sepanjang hidupnya (biasanya 3 kali dalam seminggu) atau sampai mendapat ginjal baru melalui pencangkokan yang berhasil (Brunner and Suddarth, 2008).

Namun keputusan medis bagi seorang pasien gagal ginjal untuk melakukan cuci darah merupakan suatu kepusan untuk mengeluarkan biaya hidup yang cukup besar serta kepatuhan yang cukup tinggi untuk menjalani terapi tersebut. Permasalahan yang dihadapi adalah masalah mahalnya biaya cuci darah, akibatnya tidak sedikit penderita cuci darah yang tidak patuh menjalani terapi hemodialisa sehingga tidak sedikit juga penderita yang meninggal dunia (Lumentah,2008).

Dari survei awal yang dilakukan peneliti, di dapatkan data bahwa penderita gagal ginjal kronik di RSUP H. Adam Malik Medan pada bulan September Desember tahun 2013 terdapat sebanyak 701 orang, dan pada bulan januari 2014 terdapat 110 pasien yang mengalami hemodialisa rutin. Dan dari 110 pasien tersebut terdapat $80 \%$ mengalami komplikasi intradialisis pada saat menjalani hemodialisa rutin (Medical record 2013).

Dari survey awal yang dilakukan di RSUP Haji Adam Malik Medan ditemukan bahwa pasien yang mengalami penyakit gagal ginjal kronik kebanyakan tidak mematuhi jadwal terapi Hemodialisa yang dianjurkan oleh Dokter. Maka dari itu peneliti tertarik untuk mencari apa yang berhubungan terhadap ketidak patuhan pasien gagal ginjal kronik menjalani terapi Hemodialisa dilihat dari pengetahuan dan sikap pasien di RSUP Haji Adam Malik Medan.

\section{METODE PENELITIAN}

Jenis penelitian ini merupakan penelitian analitik kuantitatif dengan menggunakan desain penelitian crosssectional, yang bertujuan untuk menganalisa hubungan pengetahuan dan sikap pasien Gagal ginjal kronik terhadap kepatuhan dalam menjalani terapi hemodialisa. Penelitian dilakukan di ruangan Hemodialisa RSUP H. Adam Malik Medan pada bulan Desember 2013 - Juli 2014. Populasi dalam penelitian ini adalah seluruh pasien gagal ginjal 
kronik yang menjalani terapi Hemodialisa dari bulan April - Juni 2014 sebanyak 110 orang dengan sampel 86 orang. Jenis data dalam penelitian ini adalah data primer dan sekunder. Data primer yaitu data yang diperoleh langsung dari responden dengan menggunakan kuesioner dan observasi langsung. Data sekunder adalah data yang diperoleh dari medical record RSUP H. Adam Malik Medan tentang data jumlah pasien gagal ginjal kronik yang menjalani terapi hemodialisa. Data dianalisis dengan menggunakan analisa univariat yaitu mendeskripsikan besarnya persentase pada seluruh variabel penelitian dan disajikan dalam bentuk tabel distribusi frekuensi dan analisa bivariat yang merupakan kelanjutan dari analisa univariat dengan cara tabulasi silang dengan menggunakan uji statistik chi-square $\left(\mathrm{x}^{2}\right)$ dengan taraf kepercayaan $95 \%$ dengan menggunakan untuk melihat hubungan pengetahuan dan sikap terhadap pelaksanaan terapi hemodialisa. Apabila nilai $\mathrm{p}<\alpha(\mathrm{p}<0,005)$ berarti ada hubungan yang signitifikan antara kedua variabel yang diteliti, Ha diterima. Apabila nilai $p>\alpha(p>0,05)$ berarti tidak ada hubungan yang signifikan antara kedua viriabel yang diteliti, Ho ditolak. (Sudjana, 2003).

\section{HASIL PENELITIAN DAN PEMBAHASAN}

\section{Hasil Penelitian}

\section{Analisa Univariat}

Dari hasil observasi terhadap 86 responden gagal ginjal kronik diketahui pengetahuan responden terhadap pelaksanaan hemodialisa sebanyak 13 responden $(15,1 \%)$ baik, 45 responden (52,3\%) cukup dan sebanyak 28 responden $(32,6 \%)$ kurang. Sikap responden menunjukkan positif sebanyak 66 responden $(76,7 \%)$ dan negatif sebanyak sebanyak 20 responden $(23,3 \%)$.

\section{Analisa Bivariat}

Analisa bivariat bertujuan untuk mengetahui hubungan yang bermakna antara pengetahuan dan sikap pasien GGK terhadap kepatuhan dalam menjalani terapi hemodialisa di Ruang Hemodialisa RSUP H. Adam Malik Medan Tahun 2014.

Berdasarkan hubungan antara pengetahuan pasien dengan kepatuhan dalam menjalani terapi hemodialisa diperoleh hasil dari 13 responden $(15,1 \%)$ dengan pengetahuan baik seluruhnya patuh dalam menjalani terapi hemodialisa. Dari 45 responden $(52,3 \%)$ dengan pengetahuan cukup mayoritas sebanyak 29 responden $(33,7 \%)$ tidak patuh dan sebanyak 16 responden $(18,6 \%)$ patuh dalam menjalani terapi hemodialisa. Dan dari 28 responden $(32,6 \%)$ dengan pengetahuan cukup mayoritas sebanyak 24 responden $(27,9 \%)$ tidak patuh dan sebanyak 4 responden $(4,7 \%)$ patuh dalam menjalani terapi hemodialisa. Hasil analisis Chi-square diperoleh nilai $p$ value $=0,00(p<0,05)$ dengan tingkat kepercayaan $95 \%$. Hal ini menunjukkan secara statistik bahwa terdapat hubungan yang bermakna antara pengetahuan dengan kepatuhan terapi hemodialisa.

Berdasarkan hubungan antara sikap pasien dengan kepatuhan dalam menjalani terapi hemodialisa diperoleh hasil dari 66 responden $(76,7 \%)$ dengan sikap positif mayoritas sebanyak 43 responden $(50 \%)$ tidak patuh dan sebanyak 23 responden $(26,7 \%)$ patuh dalam menjalani terapi hemodialisa. Dan dari 20 responden $(23,3 \%)$ dengan sikap negatif masing-masing memiliki kepatuhan yang sama dalam menjalani terapi hemodialisa yaitu sebanyak 10 responden (11,6\%). Hasil analisis Chisquare diperoleh nilai $p$ value $=2,22(p>0,05)$ dengan tingkat kepercayaan 95\%. Hal ini menunjukkan secara statistik bahwa tidak terdapat hubungan yang bermakna antara sikap dengan kepatuhan terapi hemodialisa.

\section{PEMBAHASAN}

\section{Hubungan Pengetahuan Terhadap Kepatuhan Terapi Hemodialisa}

Berdasarkan hasil penelitian yang dilakukan diruangan hemodialisa RSUP H. Adam Malik Medan Tahun 2014 diketahui bahwa mayorita pasien berpengetahuan cukup dengan kepatuhan pelaksanaan terapi hemodialisa yaitu sebanyak $45(52,3 \%)$ pasien. Berdasarkan hasil analisis menunjukkan bahwa adanya hubungan yang signifikan antara pengetahuan dengan kepatuhan pelaksanaan terapi hemodialisa. Hal ini dibuktikan berdasarkan hasil analisis chi-square antara Hubungan Pengetahuan Terhadap Kepatuhan pasien dalam menjalani terapi Hemodialisa diperoleh nilai $\mathrm{p}=$ $0,00<0,05$. Dengan tingkat kepercayaan $95 \%$, hal ini berarti ada hubungan antara pengetahuan dengan kepatuhan pelaksanaan hemodialisa. Dari hasil penelitian dapat dilihat juga bahwa masih ada pasien berpengetahuan kurang baik dengan pelaksanaan terapi hemodialisa, ini terjadi dikarenakan masih rendahnya pengetahuan pasien yang ditandai masih rendahnya pendidikan pasien tersebut. Hasil penelitian ini sesuai dengan teori yang dikemukakan oleh notoadmodjo tahun 2007 yang mengatakan pengetahuan adalah hasil tahu dan ini terjadi setelah orang melakukan penginderaan terhadap suatu objek tertentu, bahwasanya pengetahuan sangat berpengaruh terhadap tindakan seseorang karena tindakan yang didasari pengetahuan akan lebih baik dari pada yang tidak didasari pengetahuan. Dan semakin tinggi pengetahuan seseorang maka akan semakin baik tindakannya.

\section{Hubungan sikap terhadap Kepatuhan Terapi Hemodialisa}

Berdasarkan hasil penelitian yang dilakukan diruangan hemodialisa RSUP H. Adam Malik Medan Tahun 2014, diketahui bahwa mayoritas pasien memiliki sikap yang positif dengan kepatuhan terapi hemodialisa yang baik sebanyak 23 pasien, dan responden yang memiliki sikap negatif dan patuh terhadap pelaksanaan hemodialisa sebanyak $10(11,6 \%)$. Hal ini berkaitan dengan teori Notoatmodjo tahun 2007 bahwasanya sikap merupakan kesiapan dan kesediaan untuk bertindak dan bukan merupakan pelaksanaan motif tertentu, oleh karena itu kesiapan dan kesediaan sikap yang positif akan menghasilkan tindakan yang baik. Berdasarkan hasil analisis chi-square hubungan sikap terhadap kepatuhan hemodialisa diperoleh nilai $p$-value : 2,22 berarti $p>0,05$. 
Hal ini menunjukkan secara statistik bahwa tidak terdapat hubungan yang bermakna antara sikap dengan kepatuhan hemodialisa.

\section{KESIMPULAN DAN SARAN}

\section{Kesimpulan}

Dari hasil penelitian hubungan pengetahuan dan sikap pasien gagal ginjal kronik (GGK) dengan kepatuhan dalam menjalani terapi hemodialisa Di Ruangan Hemodialisa RSUP H. Adam Malik Medan Tahun 2014 dengan jumlah responden 86 orang, dapat diambil kesimpulan bahwa responden yang patuh adalah responden yang memiliki pengetahuan baik sebanyak 13 0rang $(15,1 \%)$ dan responden yang memiliki pengetahuan cukup sebanyak 16 orang $(18,6 \%)$ sedangkan responden yang tidak patuh adalah responden yang memiliki pengetahuan kurang sebanyak 4 orang $(4,7 \%)$. Sikap positif dan patuh terhadap pelaksanaan hemodialisa sebanyak 23 orang (26,7\%). Responden yang memiliki sikap negatif dan patuh terhadap pelaksanaan hemodialisa sebanyak 10 orang $(11,6 \%)$. Berdasarkan hasil uji chi-square diketahui ada hubungan yang signifikan antara pengetahuan dengan kepatuhan dalam menjalani terapi hemodialisa sedangkan sikap tidak memiliki hubungan yang signifikan dengan kepatuhan dalam menjalni terapi hemodialisa di Ruang Hemodialisa RSUP H. Adam Malik Medan Tahun 2014.

\section{Saran}

Disarankan bagi Institusi Pelayanan Kesehatan sebagai bahan masukan dalam melakukan tindakan keperawatan serta merancang program pelayanan keperawatan GGK lebih baik bagi pasien gagal ginjal kronik dalam menjalani hemodialisa. Terhadap pasien yang mempunyai sikap yang positif dengan pelaksanaan terapi hemodialisa yang baik agar lebih tetap dipertahankan dan lebih ditingkatkkan lagi. Dan bagi pasien yang bersikap negatif agar patuh dalam menjalani terapi hemodialisa. Untuk institusi pendidikan hasil penelitian ini dapat berguna untuk menambah wawasan dan pengembangan ilmu terutama tentang hubungan pengetahuan dan sikap pasien gagal ginjal kronik dalam menjalani hemodialisa.

\section{DAFTAR PUSTAKA}

Alimul, Aziz, 2012. Riset Keperawatan dan Teknik Penulisan Ilmiah. Jakarta : Salemba Medika

Arikunto, 2010. Praktek Prosedur Penelitian Suatu Pendekatan. Edisi S. Jakarta : Rineka Cipta.

Azwar, Saifuddin. 2007. Sikap Manusia. Yogyakarta: pustaka pelajar

Brunner dan Suddarth, 2011. Keperawatan Medikal Bedah, Edisi 9, Vol. 2, Jakarta : EGC. Jakarta.

Cahyaningsih, N. 2008. Hemodialisis, Mitra cendikia Press, Yogjakarta

Lumentah, N. 2008. Penyakit ginjal, Gunung Mulia, Jakarta

Notoatmodjo, soekidjo. 2010. Ilmu Perilaku kesehatan. Jakarta: Rineka Cipta.

Notoatmodjo, S, 2010. Metode Penelitian Kesehatan, Edisi Revisi. Rineka Cipta : Jakarta.

Notoatmodjo, Soekidjo. 2007. Promosi kesehatan dan ilmu perilaku. Jakarta: Rineka cipta.

Padila.,S.Kep.,Ners 2012 Keperawatan Medikal Bedah, Nusa Medika: Bengkulu

Pernefri, 2011. perilaku penderita gagal ginjal kronik dalam menjalani Hemodialisa, 6 Mei 2011.

PERNEFRI. 2012. Naskah Lengkap, workshop \& symposium nasional Peningkatan Pelayanan Hemodialisa, Penyakit Ginjal Dan Aplikasi Indonesia Renal Registry Joglosemar.

Rully, 2011 pasien gagl ginjal kronik di Indonesia. 10 Januari 2011.

Sugiono, 2012 metode penelitian pendidikan. Alfabeta, Bandung

Vita Health, 2008. Gagal Ginjal. PT. Gramedia Pustaka: Jakarta.

Zuraidah, 2012. Panduan Penyusunan Karya Tulis Ilmiah (KTI), Politeknik Kesehatan Kemenkes: Medan. 